\title{
Smart Cities: An Innovative Solution for Ongoing Operations
}

\author{
Vinod Narvekar \\ ME. Student, Dept. Of Comp. Engg. Siddhant \\ College of Engineering, Sudumbare, Pune, \\ Maharashtra, India
}

\author{
Deepak Gupta \\ Professor, Dept.Of Comp.Engg.Siddhant College \\ of Engineering, Sudumbare, Pune, Maharashtra, \\ India
}

\begin{abstract}
The Internet of Things (IoT) might have the capacity to consolidate straightforwardly and flawlessly countless and heterogeneous end frameworks, while giving open access to choose subsets of information for the improvement of a plenty of computerized administrations. Building a general engineering for the IoT is hence forth an exceptionally complex undertaking, chiefly as a result of the greatly extensive assortment of gadgets, connection layer advancements, and administrations that might be included in such a framework. In this framework is gathering activity by national and power amid a Common stage. Therefore in this paper an attempt is created to propose the android application which might solve the above mentioned issues. Moreover, the paper can gift and discuss the technical solutions and bestpractice tips of sensible town project.
\end{abstract}

\section{Keywords}

Android, Latitude and Longitude, Global Positioning System (GPS), Global System for Mobile Communications (GSM).

\section{INTRODUCTION}

Center has propelled a site named Prajavani through that open will post the petitions or grievances inside the site and discover them fathomed in an exceptionally insignificant time and may conjointly get a handle on the remaining of the protestation or appeal to he has held up at any time[2]. Toward the begin telephones were essentially utilized for business or messaging. Presently a-days, the situation has altered. In this day and age, extra concentration is given on the accessibility of the web and consequently exploitation various applications show inside the android advertises [3].

These days wastage contamination will increment at partner degree fear rate wherever the globe. It's the chief purpose for contamination. The focal point of a town relies on upon its refinement of Air, cleanliness of the streets and interstates and general its nearby air. People living inside the town must be constrained to experience the ill effects of various causes if the condition spasmodic. Entirely unexpected assortments of Diseases opened up. It turns out to be sturdier to control a sound life for people. Nonetheless, people will battle with this drawback by raising their hand to make up a sound town. The fundamental reason for this venture is to help the overall population in knowing their place points of interest and acquiring their issues settled in on-line while not getting to the officer regularly till the matter is fathomed. By this procedure the overall population will spare his time. Increasingly the venture conjointly plans to create application which can encourage the client all through mischance [5]. We habitually observe that once a mischance happens the individual or the people close-by need to physically call the crisis administrations. For the most part it happens that one individual sits tight for contrasting option to call that outcomes in misuse of your time [5]. In this manner there's a postponement for crisis administrations to achieve the circumstance of the mischance and giving essential social insurance which can even bring about death of the people met in mishap.

\section{LITERATURE REVIEW}

A number of the dreams of shrewd urban areas from innovation sellers are very sterile, not withstanding, with the gathering of gigantic informational collections and their examination taking into account the expulsion of the human from the basic leadership handle computerized advancements are seen as preferred chiefs over people. While this might be valid in numerous situations, it is not really the situation for the majority of the utilization cases for brilliant urban communities. An approach is required that considers the large number of specialized design perspectives. This article concentrates on the framework engineering advancement required all together convey the creative new "Smart city" [1] plans of action proposed inside the city setting.

Advantages: "perceptual computing" programming improvement units (SDKs) that permit gadgets to "peruse" the outward appearances of their clients are developing and beginning to be inserted into cell phones. These advancements will take into account new plans of action to be made around keen urban communities; for instance, an associated camera could be utilized to send pictures of an ineffectively repaired street in a nearby neighborhood, or an application could "read" the enthusiastic reactions of end clients when they are specifically zones of the city.

Limitation: Confirmation to outsider servers that the information from the versatile system is really from whom it says it is through the portable system validation and approval instruments.

In [2], they portray a pragmatic acknowledgment of an Internet-of-Things (loT) design at the University of Padova, Italy. Their system traverses the floors of various structures inside the Department of Information Engineering, and is intended to give access to essential administrations, for example, ecological observing and confinement to University clients, and additionally to oversee benefit get to in view of client parts and approvals.

Advantages: Fast availability and similarity with prior models, fitting and-play establishment of WSNs, quick advancement of uses and additionally the likelihood of incorporating with existing Web administrations created for standard IF systems.

Limitation: Due to high elements incorporated this framework required more calculation regarding stockpiling.

Catherine E. A. Mulligan, Magnus Olsson in [3] presents Smart urban communities have quickly turned into a hotly 
debated issue inside innovation groups, and guarantee both enhanced conveyance of administrations to end clients and diminished ecological effect in a period of uncommon urbanization. Both substantial cutting edge organizations and grassroots native drove activities have started investigating the capability of these advancements. Huge hindrances stay to the effective rollout and organization of plans of action illustrated for brilliant city applications and administrations.

Advantages: The framework arrangement catches esteem chain connections inside it and the power connections inside plans of action can move quickly as an after effect of moderately little specialized changes.

Limitations: It requires end clients are given the best administration. This will produce trust inside the keen city frameworks, with end clients given direct. Control over their information streams, empowering both top-down and base up ways to deal with urban engagement.

Individuals are presently a "city planet" [4]. Starting at 2007, 50 percent of the total populace was living in urban communities as opposed to country regions. Besides, urban communities will keep on growing it is anticipated that 70 percent of the total populace will live in urban communities by 2050. Notwithstanding this essential move in the association of human culture, they likewise confronted with expanding regular asset imperatives, stamped increments in populace, and a rebuilding of the worldwide economy. Existing urban areas and the new ones that will be fabricated will in this way need to deal with huge pressures in three circles at the same time: ecological effect, monetary development, and social advancement.

Advantages: They can unmistakably recognize stage parts that are being taken up by urban communities in various parts of the world. These distinctive parts have their own particular benefits and outcomes that would should be investigated in more noteworthy detail in future research. This typology nonetheless, can be an underlying device for city governments to consider their own particular part inside the esteem arrange and the potential stage flow at play when they are included in portable administration arrangement.

Limitation: A much clearer meaning of what control over resources and clients implies in this setting is required, while growing more connected empowering and obliging components and arrangement suggestions city governments can go to work with towards giving convincing versatile city administrations.

In [5], Accident discovery frameworks diminish fatalities coming from auto crashes by diminishing the reaction time of crisis responders. Cell phones and their locally available sensors, (for example, GPS collectors and accelerometers) are promising stages for building such frameworks. This paper gives three commitments to the investigation of utilizing cell phone based mischance location frameworks. They depict answers for key issues connected with distinguishing car crashes, for example, avoiding false positives by using versatile setting data and surveying locally available sensors to recognize vast increasing speeds.

Advantages: They are vehicle autonomous, progressively unavoidable, and give rich information to mishap examination, including pictures and recordings.

Limitation: Cell phone based mischance identification applications must give comparative data. Without direct access to ECUs, be that as it may, it is harder to gather data about the vehicle.

In [6], after the burst of the website rise in the fall of 2001, the Internet has turned into a participative medium, which permits clients to collaborate with each other and with the administrations from anyplace and whenever. They will portray the principle parts of the system, their connections and that it is so easy to build up any custom IoT application incorporating any number and kind of shrewd things. Specifically, they will demonstrate how distinctive things can be coordinated in the system, how they interface and how clients can abuse this cooperation's to build up any intricate usefulness. At last, they depict a normal HealthCare application for the IoT acknowledged utilizing Web-IoT.

Advantage: Internet of Things give propelled capacities to the universal get to and control of any keen protest. With the end goal for applications to completely misuse this potential, they require a basic yet flexible UI and advancement system.

Limitation: This framework need to assess the specialized achievability of transportation modules as isolated bits of the system, in order to empower stacking them at run time on the application server through the WebIoT interface itself.

In [7], Cities today confront expanding challenges with regards to giving progressed (computerized) administrations to their body electorate. The dangerous development in fame of versatile Internet, portable applications, and cell phones, the expanded availability of gadgets and the Internet of Things. The quick advancement in the segment and the developing complexities of their (stage) plans of action stance noteworthy difficulties for city governments needing to have an influence in this biological community. Also, existing investigative systems neglect to catch the specific (plan of action) challenges urban areas confront in conveying administrations to subjects.

Advantages: They connected a "plan of action rationale" to the instance of portable city benefits, and extended and reclassified a current structure to better catch these particular difficulties. This prompted to a point by point system of subjective parameters that should be considered while talking about open plans of action for portable city benefits and brought about a disentangled variant of the structure that can be an intense device for city governments in adjusting their arrangement objectives to their versatile administration activities

Limitation: Existing systematic structures neglect to catch the specific (plan of action) troubles urban communities confront in conveying administrations to residents.

\section{METHODS IN PROPOSED SYSTEM}

As appeared in figure 1 the proposed framework is isolated into two modules:

At first client can catch the picture of trash or harmed street and set priority to it grievance and enroll the grievance by bringing on the data. The enrolled protestations will be at main desk area here the objections are partitioned by and refuse division. As of now the grievance can move to sub desk area, sub desk area will sort the complaints of the client with regards to the priority given by them. Sub work area can forward the data to the service provider as per the priority given by client. The service provider make a move for assurance the trash and street associated issues. At that point react message is given to client. 
In second Module: User will send the demand of encourage message to the framework. The client met with accident chooses weather he/she is conscious or un-conscious. On the off chance that client chooses the conscious than the enlisted client information furthermore the present area of the accident place will be sent to the framework. In the event that client is un-conscious then the other individual is sending the demand for encourage him/her will pick the un-conscious and send the information. Framework can produce the rundown of close police headquarters and hospital facilities. Client chooses the police headquarters and accordingly the mischance information message will be sent to close police headquarters and in this way the grievance is enrolled then client chooses the nearby hospital center wherever the police base camp sends the message with respect to enlisted grievance.

At the point when a client enters a record question first time, the framework will seek that document in unstructured superpeers database and imprints that document ask for in bloom filter. In the event that a similar record ask for comes more than 3 times here, we set the edge as check 3 i.e. the framework will make the reproduction of that demand record and makes the intrigue group with hunt inquiry name to that bunch. On the off chance that next time same inquiry ask for comes then framework will looks that document intrigue group in light bloom filter record.

\subsection{System Model :}

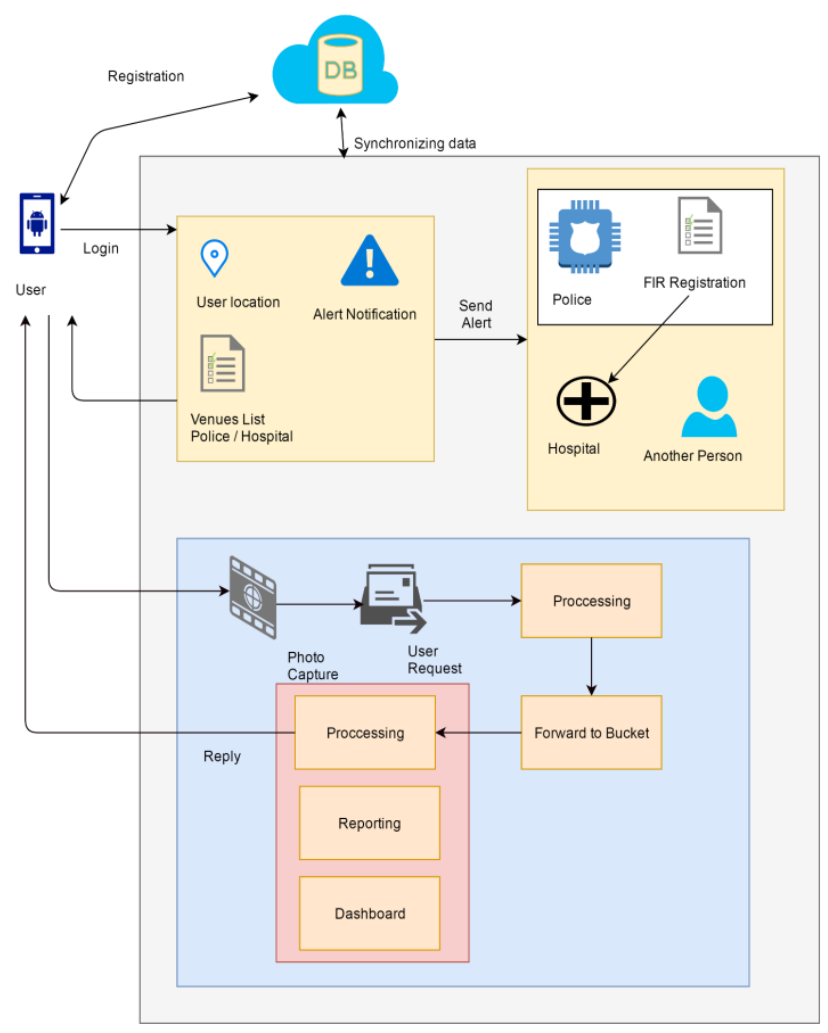

Fig 1: Architecture diagram of proposed system

\subsection{Architecture Description:}

User registers himself/herself in system. User information is store into database. Then user login in system that time user location is fetch. User can raise complaint for Garbage, Road network. User take photo and send request for processing.

\subsection{Implementation of modules}

Garbage Module: User take photo of garbage and send request for process at same location multiple user send same complaint then garbage head can view complaint and number of count of same request.

Road Network Module: User take photo of road network and send request for process. At the same location multiple user send same complaint then road network head can view complaint and number of count of same request.

Reporting Module: System generate report according to status of request. User can view status in report model.

SMS service: User receive unique complaint id by SMS on user mobile number.

\subsection{Considerations}

\section{Estate - One Ward}

People Profile: Commissioner, one Corporator, one Admin Staff, three Main Desk Staff, three Sub-desk Staff, three Service providers.

Login and Access: Access is provided based on the role for all profiles mentioned in the above people profiles.

Commissioner: To view reports and take decisions

Corporator: View reports, and escalate the issue to Service provider

Admin Staff : Login and review the SR status, ensure the SRs are getting assigned and actioned. Ensure the Service providers are auctioning the requests and closing properly.

Main Desk - Login and assign the SR to respective sub desks, Change the priority as per the severity. Extract report and check the SR status.

Sub-desk: Login and assign the SRs to respective Service providers, escalate the if the SR is not being addressed by any Service provider, extract the report and review.

Service Provider: Login and accept the assigned SRs, take appropriate action and update the SR. Close the actioned SRs and provide the feedback.

User Login: registration with mobile number and Adhar number, Login and raise the requests, track the request status, provide the feedback to service providers.

\subsection{Module-1}

\subsubsection{User Query:}

In this module there's user which should register initial into the system. The user takes the image of the garbage or road damaged and sets priority to it and sends the information to the most table .i.e. user register the grievance. More the user will see the process of the grievance followed by the service is provided by service supplier.

\subsubsection{Main desk:}

The user request is processed by main desk wherever they're going to divide the complaints associated with road and garbage and send the data to related department.

3.5.3 Sub desk:

Complaint are going to be sent to sub desk from the main table. Complaints are sorted in step with the priority given by user and sent to the service providers. 


\subsubsection{Service Providers:}

Once the user registers the grievance it'll be sent to the main desk and main desk divides the complaints in step with the garbage and road department. Then the information are shared to sub desk wherever the priority is taken into account and consequently the service provider get the information of the grievance and take action. Once completion of the work the notification are sent to user.

\subsection{Module-2}

\subsubsection{Generation of Query:}

In this module there's user which has to register initial into the system. At the time of login user should be choose that he / she is conscious or unconscious. Using the Username and parole user login the system. Then choose the choice that's conscious or not then send the request which will goes to the police and hospitals. It depends thereon whether the user is conscious or not. This request can goes to the closest location of police and hospital.

\subsubsection{GPS Tracking:}

When the request is generated by the user, at the background looking the closest location of police and hospital when looking done that request with success send to it locations. During this the user current location additionally used. On the premise of this location of user the request of the user goes to nearest hospital and police.

\subsubsection{Processing on Query:}

After the request with success sent to the hospital and police the alert to the user within the sort of massage. Therein the thriving response is gift and FIR registration alert additionally as well as. Alert notification can generate to police and hospital additionally within the sort of the user request. Hospital may see the alert related to FIR that is registered related to the accidental person.

\subsection{Third-Party Provider Solutions}

For previous couple of years, a vast varies of third-parties providing to deliver alert messages (and all completely different info services) via text transmission services. The design of those systems is comparatively easy. Whether or not or not activated through an online interface, directly from a phone, or as code running on a field administrator's PC, these services act as SMS aggregators and inject text messages into the network. Among the event of an emergency message is shipped to the service centre from the victim or footer mobile.

\subsubsection{Short Message Service}

Short Message Service (SMS) is a text transmission service part of phone, web, or mobile communication systems, exploitation standardized communications protocols that modification the exchange of short text messages between mounted line and itinerant devices.

\subsubsection{GPS Technology}

The Global Positioning System (GPS), additionally aforementioned as Navstar, may possibly be a world navigation satellite system (GNSS) that has location and time information altogether atmospheric condition, anyplace on or close to the planet wherever there's qualification clear line of sight to four or many GPS satellites. The GPS system operates severally of any telecommunication or internet reception, though' these technologies will enhance the utility of the GPS positioning information. The GPS system provides essential positioning capabilities to military, civil, and industrial users round the world.

\section{Algorithm \\ K-Nearest Neighbors (KNN) algorithm:}

1. User take image.

2. At the time photo send to system location is attached to image.

3. By calculating distance from other images, check weather same request from same region is already present in system.

4. One region is about 20 meters large. If no any image from same region present then request is add it in system.

5. If same request from same region is already present then attach new request to previous request

6. Finally display first request and attached request count.

\section{Mathematical Model}

Let System $\mathrm{S}=$ Android Application.

System $\mathrm{S}=\{\mathrm{S}, \mathrm{I}, \mathrm{U}, \mathrm{O}, \mathrm{P}$, Delta, $\}$.

Where,

$\mathrm{S}=\{\mathrm{GPS}\}$.

Delta $=$ function .

$\mathrm{I}=\{\mathrm{I} 1, \mathrm{I} 2, \mathrm{I} 3\}$.

Where,

I1 =PD-> places directory which is the set of hospitals and police station.

i.e. $\mathrm{I} 1=\{$ Hospitals, Police Stations $\}$

I2=SD-> smart distance is distance between source and destination.

i.e. $I 2=\{$ Sources, Distination $\}$

I3=GR- $>$ garbage road is the image of the garbage or the damaged road with priority.

i.e. $\mathrm{I} 3=\{$ image, priority $\}$

$\mathrm{U}=$ Number of users.

$\mathrm{U}=\{\mathrm{U} 1, \mathrm{U} 2 \ldots \mathrm{Un}\}$.

$\mathrm{O}=$ output.

Delta1=I1->O1

O1 $=\{$ Phone no., Address, Map, Distance, Reviews $\}$

Delta->Cal n;

Let $\mathrm{F}(\mathrm{M})=\mathrm{Cal}(\mathrm{i})$

Where, limit 0 to $\mathrm{n}$

$\mathrm{Cal}=\{$ Dist $\}$

Where Dist $=$ Destination.

$\mathrm{I} 2=\{$ Source, $\mathrm{U} 1, \mathrm{U} 2, \mathrm{U} 3, \ldots \ldots, \mathrm{Un}\}$

Where $\mathrm{U}$ is the users.

$\mathrm{U}<\mathrm{Un}$;

Dist $=\{\mathrm{D} 1, \mathrm{D} 2, \mathrm{D} 3, \ldots \ldots, \mathrm{Dn}\}$

$[\mathrm{D}=$ Distance $]$

$\mathrm{D}=$ [Hospitals, Police Stations $]$. 
$\mathrm{D} 1=\{\mathrm{H} 1, \mathrm{H} 2, \ldots \ldots, \mathrm{Hn}\}$.

$\mathrm{D} 2=\{\mathrm{SP} 1, \mathrm{SP} 2, \ldots, \mathrm{Spn}\}$.

Source $=$ distance $[$ source $]+\sum_{i=1}^{n 1}$ distance

$\sum_{i=1}^{n 1} \mathrm{U} 1=$ source

Between [source,U1]

\section{$P$ is the procedure:}

Step 1: At first client will tap the photo of mischance scene and send the demand of message to the framework.

Step 2: System will produce the proposal rundown of adjacent areas in light of client area from where the message is gotten.

Step 3: User will choose the one area from that rundown and send the message to that area.

Step 4: Then react message is given to client inside a some edge time .If assume that client don't get reaction message then framework will consequently send that message to next closest area.

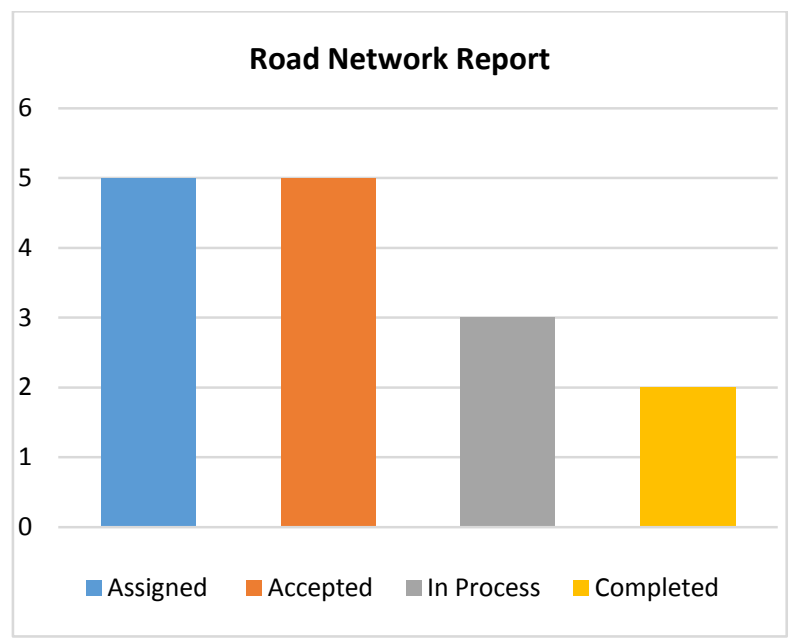

Fig 2. Road Network Report

\begin{tabular}{|l|l|l|l|}
\hline Assigned & Accepted & In Process & Completed \\
\hline 5 & 5 & 3 & 2 \\
\hline
\end{tabular}

Table 1. Road Network Report Data

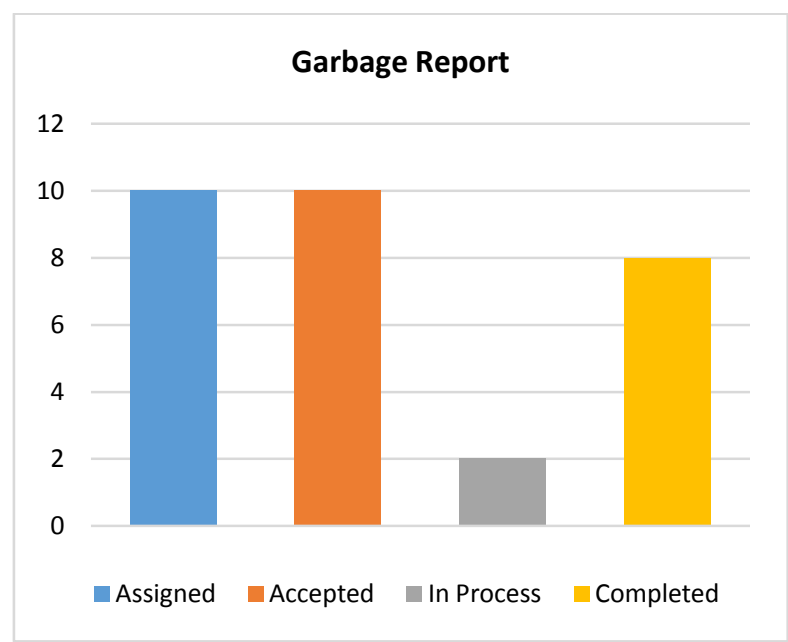

Fig 3. Garbage Report

\begin{tabular}{|l|l|l|l|}
\hline Assigned & Accepted & In Process & Completed \\
\hline 10 & 10 & 2 & 8 \\
\hline
\end{tabular}

Table 2. Garbage Report Data

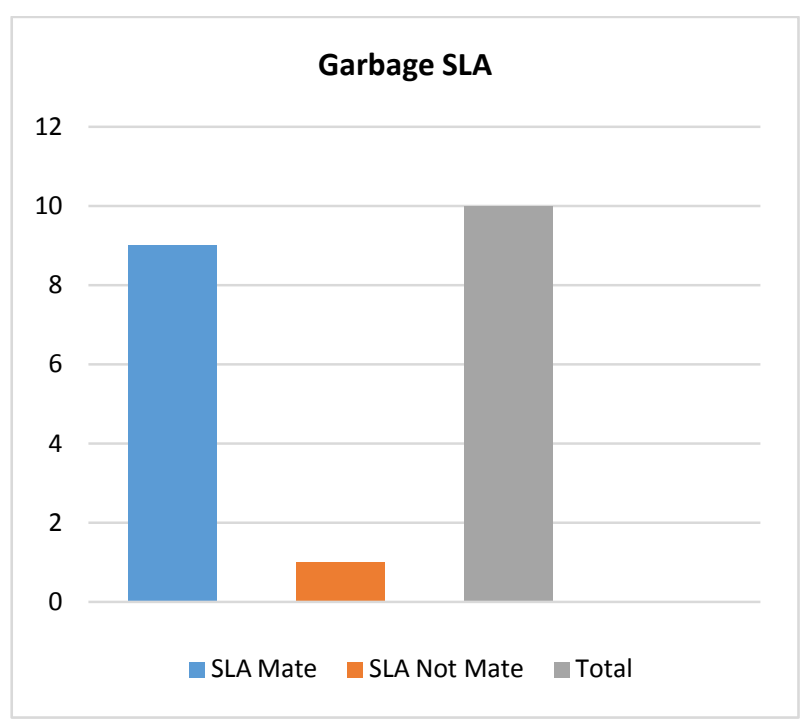

Fig 4. Garbage SLA Report

\begin{tabular}{|l|l|l|}
\hline SLA Mate & SLA Not Mate & Total \\
\hline 9 & 1 & 10 \\
\hline
\end{tabular}

Table 3. Garbage SLA Data

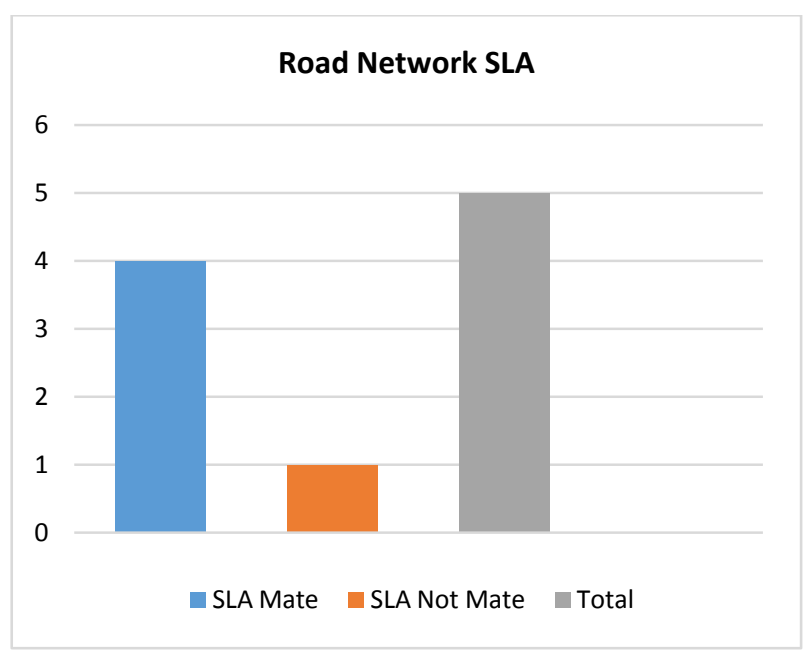

Fig 4. Road Network SLA Report

\begin{tabular}{|l|l|l|}
\hline SLA Mate & SLA Not Mate & Total \\
\hline 4 & 1 & 5 \\
\hline
\end{tabular}

Table 4. Road Network SLA Data 


\section{CONCLUSION}

Even before we tend to set our platform, our aim was to develop an application that assisted citizens with higher utilization of services provided by the Municipal Corporation inside a specific space. The android mobile platform appeared the logical alternative, because of the recognition and prevalence of the mobile software system among individuals.

Android is a software packages tack for mobile devices that has an OS, middleware, and key applications. The automaton SDK provides the tools and libraries necessary to start developing applications that run on automaton hopped-up devices. The method of learning the fundamentals of automaton application development was simplified by the varied books and developer help and learning websites that are offered in abundance. The Eclipse IDE provides a really straightforward development setting for automaton. The complete designing and development method over the previous couple of months has been a learning expertise. It's not solely increased our programming information, however additionally our understanding of the varied processes concerned in software package projected system development.

In our projected system user will take a exposure of the actual activity i.e. garbage, road network and health. the appliance can augment the present position wherever the image is taken. The above increased image is distributed to the involved authority. The priority of the criticism would be raised if the amount of them is significantly a lot of in a locality. This accident detection and alert system offer emergency responders with crucial info at the earliest possible time. Reducing the time between once associate accident takes place and once it's detected will cut back mortality rates. The complete works got to be integrated with the auto to validate its practicality and responsibility. Therefore this work can cut back the accident death magnitude relation in right smart quantity even in rural roads. Then it's a good importance in day to day lifetime of the individuals within the country like India. This projected work can offer important info concerning the accidents even in uninhabited space. This complete projected system, application and our learning and understanding of automaton has exponentially mature over the last few months.

\section{FUTURE WORK}

In Future we will develop IOS app for Apple phone users. This system can be use for other purpose like disaster management, fire request system, or any other manual system.

\section{ACKNOWLEDMENTS}

We might have to be compelled to convey the analysts and to boot distributers for making their assets accessible. We tend to boot appreciative to commentator for his or her necessary recommendations moreover convey the school powers for giving the obligated base and backing.

\section{REFERENCES}

[1] Catherine E. A. Mulligan, "Architectural Implications of Smart City Business Models: An Evolutionary Perspective"

[2] A. P. Castellani, N. Bui, P. Casari, M. Rossi, Z. Shelby, and M. Zorzi, "Architecture and protocols for the Internet of Things: A case study," in Proc. 8th IEEE Int. Conf. Pervasive Comput. Commun. Workshops (PERCOM Workshops), 2010, pp. 678-683.

[3] C. E. A. Mulligan and M. Olsson, "Architectural implications of smart city business models: An evolutionary perspective," IEEE Commun. Mag., vol. 51, no. 6, pp. 80-85, Jun. 2013.

[4] S. Brand, "City Planet," Strategy + Business, 2005.

[5] Chris Thompson, Jules White, Brian Dougherty, Adam Albright, and Douglas C. Schmidt, "Using Smartphones to Detect Car Accidents and Provide Situational Awareness to Emergency Responders",

[6] A. P. Castellani, M. Dissegna, N. Bui, and M. Zorzi, "WebIoT: A web application framework for the internet of things," in Proc. IEEE Wireless Commun. Netw. Conf. Workshops, Paris, France, 2012.

[7] A. Laya, V. I. Bratu, and J. Markendahl, "Who is investing in machine-to-machine communications?" in Proc. 24th Eur. Reg. ITS Conf., Florence,Italy, Oct. 2013, pp. 20-23.

[8] H. Schaffers, N. Komninos, M. Pallot, B. Trousse, M. Nilsson, and A. Oliveira, "Smart cities and the future internet: Towards cooperation frameworks for open innovation," The Future Internet, Lect. Notes Comput. Sci., vol. 6656, pp. 431-446, 2011.

[9] D. Cuff, M. Hansen, and J. Kang, "Urban sensing: Out of the woods," Commun. ACM, vol. 51, no. 3, pp. 24-33, Mar. 2008. 